\title{
The Promise of Enterprise Architecture for Global Health Informatics
}

\author{
Rada Hussein ${ }^{1}$
}

Received: 23 May 2017 / Accepted: 25 May 2017 /Published online: 29 May 2017

(C) Springer Science+Business Media New York 2017

$\begin{array}{ll}\text { Abbreviations } \\ \text { EA } & \text { Enterprise Architecture } \\ \text { EHR } & \text { Electronic Health Records } \\ \text { GHI } & \text { Global Health Informatics } \\ \text { HIS } & \text { Health Information System } \\ \text { HMN } & \text { Health Metrics Network } \\ \text { HSS } & \text { Health system strengthening } \\ \text { LMICs } & \text { Low and Middle-Income Countries } \\ \text { NHS } & \text { National Health System } \\ \text { SDGs } & \text { Sustainable Development Goals } \\ \text { UHC } & \text { Universal Health Coverage } \\ \text { UN } & \text { United Nations } \\ \text { WB } & \text { World Bank } \\ \text { WHO } & \text { World Health Organization }\end{array}$

\section{Global health and universal health coverage}

Global health is defined as "an area for study, research, and practice that places a priority on improving health and achieving equity in health for all people worldwide. Global health emphasizes transnational health issues, determinants, and solutions; involves many disciplines within and beyond the health sciences and promotes inter-disciplinary collaboration; and is a synthesis of population-based prevention with individual-level clinical care" [1].

This article is part of the Topical Collection on Systems-Level Quality Improvement.

Rada Hussein

rada.hussein.ahmed@gmail.com

1 El-Hay El-Swissry (B), Bldg: 8, Apt: 2, Nasr City, Cairo 11528, Egypt
Ultimately, the Universal Health Coverage (UHC) concept was emerged - as the third global health transition- to ensure that all people can receive a quality healthcare service without suffering financial risk [2]. Accordingly, UHC is considered as the essential key of the United Nations (UN) post-2015 development agenda to achieve all health-related Sustainable Development Goals (SDGs) targets by 2030 [3]. Therefore, the World Health Organization (WHO) and the World Bank (WB) are championing UHC as the most important immediate goal for global health [4].

Nevertheless, UHC can be only realized when a country has a consistent and comprehensive National Health System (NHS)- comprised of institutions, people and actions- that efficiently responds to the health challenges in order to deliver better health outcomes [3]. Such an efficient NHS must have a strong national Health Information System (HIS) that can produce reliable, timely, and good-quality data. Thus, these timely-accurate data can be used in monitoring and evaluating the overall NHS in addition to making evidence-informed decisions at different levels of the health system [5].

\section{Global health informatics and enterprise architecture}

Recently, the Global Health Informatics (GHI) discipline has been emerged-from the broader Biomedical Informatics domain- and described as "the informatics discipline focused on empowering people to use appropriate technology to provide information-based solutions with a global perspective that support health care for all. The mission of global health informatics is to share informatics knowledge, skills, and research, and foster local innovations to promote highest standards of health for all with an emphasis on low income, low resource countries and the medically underserved" [6]. In 
other words, the GHI field mainly focuses on applying informatics tools and technologies to both public health and healthcare delivery domains in Low-to-Middle Income Countries (LMICs). The broad range of such GHI applications in LMICs includes, for instance [7, 8]:

- electronic health record, telemedicine, mHealth applications -to support the delivery of public and private health services, in addition to,

- health information exchange, health registries, national HISs -to manage and monitor the public health services across the country.

Enterprise Architecture (EA) is an evolving discipline and defined as " a well-described methodology for aligning information systems with an organization's mission, goals, and objectives. It is used to produce a comprehensive description of all of the key elements and relationships of an organization and its alignment with an organization's mission, goals, and strategic objectives with information systems" [9]. Thus, EA provides a "systems thinking" view that incorporates vision and strategy, business architecture, information systems, and technology domains [5].

\section{EA and GHI are paving the way to realize the UHC goals}

For the last 20 years, Health System Strengthening (HSS) has been placed on the agenda of the global health organizations and international development agencies [10]. This is because; HSS has been considered as the core of the global health system and a key strategy to achieve the UHC Goals [3]. In 2007, the WHO developed a framework for HSS comprised of six building blocks [10], namely: 1) health services, 2) health workforce, 3) health information, 4) medical products, vaccines and technologies, 5) health financing, and 6) leadership and governance.

Nevertheless, recent studies reported that health systems in many LMICs are still weak and fragmented [11, 12]. Moreover, most of these health systems mainly focus on specific diseases programs instead of simultaneously coping with communicable and non-communicable epidemics [13, 14]. These studies also highlighted the strong potential of the GHI applications- mainly, mHealth, telemedicine, eLearning, Electronic Health Records (EHR), HIS, electronic logistics management systems and lab information systems - in HSS as well as UHC attainment [7, 11, 12].

Meanwhile, several studies adopted the EA approach -as a strategic and planning tool -for [14]:

- identifying the main HIS components, and
- modelling the HIS complex interrelated interactions into four architectural domains, namely: business, application, data and technology architectural domains.

Above all, the Health Metric Network (HMN) framework of the WHO provides a framework and standards in a phasedapproach for strengthening national HISs [15]. Accordingly, the future edition of the HMN framework will highlight the EA approach [12] to expand better understanding of the complex interrelations of the different HIS components.

In this way, the EA approach can be utilized in HIS strengthening following one of these approaches:

- either as a "top-down" approach for designing consolidated and consistent national HISs in LMICs [12], or

- as a "middle-out" approach for developing health architecture frameworks - based on the international standards for health data use and exchange- to improve the interoperability of complex HISs [13].

Fortunately, the created EA models in the recent studies have shown potential evidence in addressing various aspects of global health, such as:

- Providing a conceptual integrated view of the healthcare enterprise [16].

- Determining common requirements for national health insurance information systems [17].

- Connecting HIS utilizing a national eHealth standards framework to ensure the appropriate use of standards for interoperability [18].

- Consolidating the fragmented HIS in LMICs [13].

- Providing an architectural approach to HIS strengthening in developing countries [14].

- Creating an overarching plan for all eHealth systems in Rwanda to support maternal health care [6].

- Designing, planning and implementing a national public health surveillance system in Jordan [19].

- Developing and using EHR-Based Care Governance [20]. Additionally, there are early initiatives for implementing national shared health records - utilizing open source health information exchanges- in Ghana, South Africa, Philippine, Kenya and Rwanda [12].

- Planning and designing national eHealth EA frameworks for consolidating and expanding the current HISs into more coherent and integrated ones in Ghana, Rwanda and South Africa [13].

In summary, utilizing the EA approach will play a pivotal role in designing and implementing integrated and coordinated national HISs for global health. On the other hand, EA- as a strategic and planning tool- along with GHI will support the development of reusable software components and models for 
future global health projects. As a result, EA and GHI will be the essential tools to strengthen the NHSs for realizing the UHC goals and improving the global health status.

\section{Compliance with Ethical Standards}

Conflict of Interest The author declares that she has no conflict of interest.

Ethical Approval This article does not contain any studies with human participants or animals performed by the author.

\section{References}

1. Koplan, J.P., Bond, T.C., Merson, M.H., Reddy, K.S., Rodriguez, M.H., Sewankambo, N.K., and Wasserheit, J.N., Consortium of universities for global health executive board, towards a common definition of global health. Lancet Lond. Engl. 373:1993-1995, 2009. doi:10.1016/S0140-6736(09)60332-9.

2. Rodin, J., and de Ferranti, D., Universal health coverage: The third global health transition? Lancet Lond. Engl. 380:861-862, 2012. doi:10.1016/S0140-6736(12)61340-3.

3. Schmets, G., Rajan, D., and Kadandale, S., Strategizing national health in the 21st century: A handbook. World Health Organization, Geneva, 2016.

4. Brearley, L., Marten, R., and O'Connell, T., Universal health coverage: A commitment to close the gap. The Rockefeller Foundation, Save the Children, UNICEF and the World Health Organization, New York, 2013.

5. MEASURE Evaluation, World Health Organization, United States Agency for International Development Module 8: Information and Communication Technology for RHIS - MEASURE Evaluation. https://www.measureevaluation.org/our-work/routine-healthinformation-systems/rhis-curriculum-modules/module-8information-and-communication-technology-for-rhis. Accessed 21 May 2017.

6. Richards, J., Douglas, G., and Fraser, H. S. F., Perspectives on global public health informatics. In: Magnuson, J. A., Fu, P. C., Jr. (Eds.), Public Health Inform. Inf. Syst. London: Springer, pp 619-644, 2014.

7. Marin, H., Massad, E., Gutierrez, M. A., Rodrigues, R. J., and Sigulem, D. (Eds.), Global health informatics: how information technology can change our lives in a globalized world, first edition. Cambridge, MA: Academic Press, 2016.

8. Dixon, B.E., Pina, J., Kharrazi, H., Gharghabi, F., and Richards, J., What's past is prologue: A scoping review of recent public health and global health informatics literature. Online J. Publ. Health Inform. 7:e216, 2015. doi:10.5210/ojphi.v7i2.5931.

9. Mwanyika, M., Lubinski, D., Anderson, R., Chester, K., Makam, M., Steele, M., and de Savigny, D., Rational systems design for health information systems in low-income countries: An enterprise architecture approach. J. Enterp. Archit. 60-69, 2011.

10. World Health Organisation, Everybody's business: Strengthening health systems to improve health outcomes - WHO's framework for action. WHO, Geneva, 2007.

11. The World Health Organization (WHO) in the African Region, Building Better Systems: Improving delivery and data in the context of UHC/ehealth. http://www.afro.who.int/index.php?option= com_docman\&task=doc_download\&gid=10560\&Itemid=2593. Accessed 21 May 2017, 2016.

12. Celi, L. A. G., Fraser, H. S. F., Nikore, V., Osorio, J. S., and Paik, K. (Eds.), Global health informatics: principles of eHealth and mHealth to improve quality of care. Cambridge, MA: MIT Press, 2017.

13. Mudaly T, Moodley D, Pillay A, Seebregts CJ Architectural frameworks for developing national health information systems in low and middle income countries. In: Proc. first Int. Conf. Enterp. Syst. ES. pp 1-9, 2013.

14. Stansfield, S., Orobaton, N., Lubinski, D., Uggowitzer, S., and Mwanyika, H., The case for a national health information system architecture; a missing link to guiding national development and implementation, Paper presented at the Making the eHealth Connection, Making the ehealth Connection Conference, Bellagio, Italy, July 13-August 8, 2008.

15. Health Metrics Network, Framework and Standards for Country Health Information Systems, Second Edition. Geneva: WHO, 2008.

16. Ahsan, K., Shah, H., and Kingston, P., Healthcare modelling through enterprise architecture: A hospital case. In: 2010 Seventh Int. Conf. Inf. Technol. New Gener. pp 460-465, 2010.

17. PATH, Determining common requirements for national health insurance information systems. Seattle: PATH, 2012.

18. Ritz, D., Althauser, C., and Wilson, K., Connecting health information systems for better health: Leveraging interoperability standards to link patient, provider, payor, and policymaker data. Seattle: PATH and Joint Learning Network for Universal Health Coverage, 2014.

19. Sheikhali, S.A., Abdallat, M., Mabdalla, S., Al Qaseer, B., Khorma, R., Malik, M., Profili, M.C., Rø, G., and Haskew, J., Design and implementation of a national public health surveillance system in Jordan. Int. J. Med. Inf. 88:58-61, 2016. doi:10.1016/j.ijmedinf. 2016.01.003.

20. Motoc, B., An enterprise architecture perspective to electronic health record based care governance. Stud. Health. Technol. Inf. 234:243-248, 2017. 